\title{
Switch-on Phenomena and Field Emission from Single-Walled Carbon Nanotubes Embedded in Glass
}

*Correspondence to:

Mousa MS,

Tel: +962-79-565-9761

Fax: +962-3-2375540

E-mail: marwansmousa@yahoo.com

Received August 18, 2017

Revised September 7, 2017

Accepted September 8, 2017

\author{
Samer I. Daradkeh, Marwan S. Mousa* \\ Department of Physics, Mu'tah University, Al-Karak 61710, Jordan
}

\begin{abstract}
In this study, we will describe a new design of carbon nanotubes tip. Single-walled carbon nanotubes produced using high-pressure $\mathrm{CO}$ over Fe particles (HiPCO) at CNI, Houston, TX used in this study. These tips were manufactured by employing a drawing technique using glass puller. Field electron microscopies with tips (cathode) to screen (Anode) separation of $\sim 10 \mathrm{~mm}$ was used to characterize the electron emitters. The system was evacuated down to base pressure of $\left(\sim 10^{-8} \mathrm{mbar}\right)$ when baked at up to $\left(\sim 200^{\circ} \mathrm{C}\right)$ over night. An electron field emission patterns, as well as current versus voltage characteristics and Fowler-Nordheim plots, are discussed.
\end{abstract}

Key Words: Cold field emission, Single-walled carbon nanotubes, Fowler-Nordheim plot

\section{INTRODUCTION}

Electron source plays an essential role in the information display. They mostly use the thermionic emission mechanism, where the electrons are emitted from heated filaments (hot cathode) (Modinos, 1984). Field emission is an alternative mechanism to extract electron where electron emitted from a surface by tunneling from a state near the Fermi level. There are several materials used for field electron emission but the most promising one is carbon nanotubes (CNTs) (Forbes, 2012; Forbes et al., 2015).

CNTs are composed of graphite sheets rolled into seamless hollow cylinders with diameter ranging from $(1 \mathrm{~nm})$ to about (50 nm) (Saito \& Uemura, 2000), CNTs discovered by lijima (1991) and it have been attached much attention as electron source for many reasons such as ultra-small radius, high aspect ratio, high electrical conductivity (Zhang et al., 2005), high chemical stability and high mechanical strength (Bani Ali \& Mousa, 2016), CNTs offer several advantages over other emitters material such as enhanced current stability, low threshold voltage, long lifetime (Hong et al., 2009) and high emission current density. These emission characterizations are directly related to the unique structure and chemical bonding of the CNTs (Cheng \& Zhou, 2003). And for previous reason, we use single-walled carbon nanotubes (SWCNTs) to study the field electron emission.

\section{MATERIALS AND METHODS}

\section{Theory}

Field electron emission was explained in 1928 by combining quantum tunneling theory with Fermi-Dirac statistical theory. The theory of field electron emission from bulk metals was proposed by Ralph H. Fowler and Lothar W. Nordheim, this phenomenon can be described by a family of the approximate equation called "Fowler-Nordheim type equation", is named after them. Strictly speaking, these equations apply only to field emission from bulk metal, but the theory often usedas a rough approximation-to describe field emission from other material (Ala'a et al., 2015). The original FowlerNordheim type (FN-type) equation was developed using several hypotheses and some simplify assumption. Thus FN: (1) assumed a smooth, flat, planar emitter surface, with constant electric field outside it; (2) disregarded details of emitter atomic structure; (3) ignored what would now be called the exchange-and-correlation interaction between the escaping electron and the emitter surface; (4) assumed a Sommerfeld-type free-electron model for the emitter electron

(a) This is an open-access article distributed under the terms of the Creative Commons Attribution Non-Commercial License (http://creativecommons.org/licenses/by-nc/4.0) which permits unrestricted noncommercial use, distribution, and reproduction in any medium, provided the original work is properly cited.

Copyrights @ 2017 by Korean Society of Microscopy 
Table 1. The development of FN equations

\begin{tabular}{lll}
\hline \multicolumn{1}{c}{ FN-type equation } & \multicolumn{1}{c}{ Area of use } & \multicolumn{1}{c}{ Identify terms } \\
\hline$J_{L}=a \varphi^{-1} F_{L}^{2} \exp \left(-b \varphi^{\frac{3}{2}} F_{L}\right)$ & Elementary, for LECD & $\varphi$ : work function \\
& & a\&b: first and second FN constant \\
& & $\mathrm{F}_{\mathrm{L}}$ : local surface electric field \\
$J_{L}=P^{F N} a \varphi^{-1} F_{L}^{2} \exp \left(-b \varphi^{\frac{3}{2}} / F_{L}\right)$ & Original, for LECD & $\mathrm{P}^{\mathrm{NN}}$ : tunneling prefactor \\
$J_{L}=t_{F}^{-2} a \varphi^{-1} F_{L}^{2} \exp \left(-v_{F} b \varphi^{\frac{3}{2}} / F_{L}\right)$ & Standard or Murphy-Good equation, & $t_{F} \& v_{F}$ : particular value of mathematical function $v$ and $t$ \\
& for LECD & where $v$ and $t$ are sometimes called field emission elliptic function. \\
$J_{L}=\lambda_{L} a \varphi^{-1} F_{L}^{2} \exp \left(-v_{F} b \varphi^{\frac{3}{2}} / F_{L}\right)$ & Technically complete, for LECD emitter & $\lambda_{L}$ : pre- exponential correction factor \\
$J_{M}=\alpha_{M} \lambda_{C} a \varphi^{-1} \gamma_{C}^{2} F_{M}^{2} \exp \left(-v_{F} b \varphi^{\frac{3}{2}} / F_{L}\right)$ & Technically complete, for LAFE & $\gamma_{c}$ : characteristics macroscopic field enhancement factor \\
& & and defined by $\left(\mathrm{F}_{\mathrm{C}} / \mathrm{F}_{\mathrm{M}}\right)$ \\
\hline
\end{tabular}

FN, Fowler-Nordheim; LECD, local emission current density; LAFE, large area field emitter.

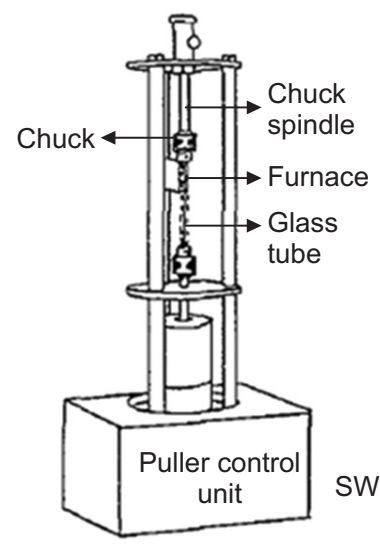

$1 \mathrm{~mm} \phi$
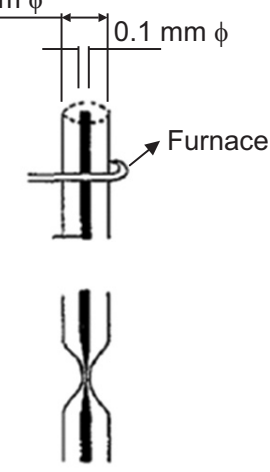

SWCNTs

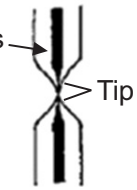

Fig. 1. Schematic diagram of the glass puller. SWCNTs, single-walled carbon nanotubes.

states; (5) assumed electrons obeyed Fermi-Dirac statistics; and (6) approximated emitter temperature as $0 \mathrm{~K}$ (Forbes, 2012).

Cold field emission (CFE) from bulk metals is described by a family of the approximate equation called FN-type equations. These equations were derived for material situations where emission comes from a degenerate metal like conduction band of sufficient depth, and quantum-confinement effects (Forbes, 2010; Qin et al., 2011).

The equations have involved repeated improvement and reformulation of theoretical approaches, the Table 1 show how FN equation developed over years (Forbes, 2010).

And the development still going on to apply the FN equation on the nanoscopic field emitter, more specifically in (Edgcombe, 2005) and (Edgcombe \& Jonge, 2007) develop a formula used for sphere on a cone model (large anode-tip distance), other works are, the hyperboloid by (Zuber et al.,

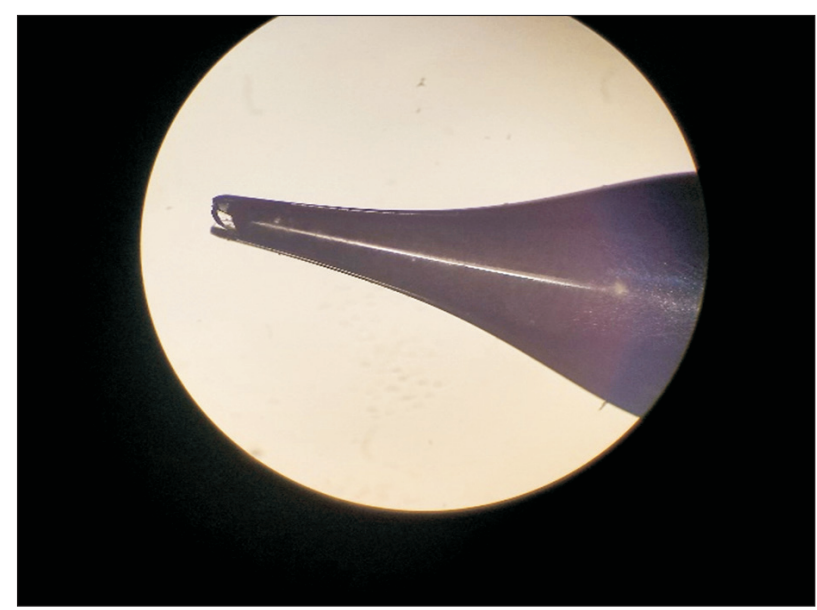

Fig. 2. Optical micrograph of (CNT-10) tip at 50× magnification. CNT, carbon nanotubes.

2002) in which the emission from a single surface element $\mathrm{dS}$ in considered to be FN type, and the derive a generalized FN equation for nanoscopic field emitters by (Kyritsakis \& Xanthakis, 2014).

\section{Experimental Setup}

This study uses SWCNTs are produced by catalytic conversion of high-pressure CO over Fe particle (HiPCO) processed at CNI, Houston, TX, where the length of individual and SWCNT is approximately $1 \sim 3 \mu \mathrm{m}$, and the mean diameter is $1 \sim 4 \mathrm{~nm}$, and the emitter produced by using a "glass puller" to, it's a technique for pulling heated glass capillary tubes into fine points. The apparatus is shown in Fig. 1.

Two bearing are located accurately on plates supported by three stainless steel rods fixed rigidly to the frame of the unit control unit. This frame is strong enough to serve as a stable base for the instrument. The glass tube fits inside these bearings between the upper and lower chucks with the furnace loop located around it. The lower chuck spindle slides vertically to pull down the glass tube under the influence of 
gravity. As the temperature of the furnace is raised to the soften point of the glass the tube necks as shown in Fig. 1 (Mousa \& Hibbert, 1993), the SWCNTs were entered into the opposite end of each glass tube so they would protrude at the tip end, the final result as shown in Fig. 2 (Marwan et al., 2015).

The sample placed inside ultra-high vacuum system which the axial tip-to-screen separation was fixed at around (10 $\mathrm{mm})$. The standard producer was to bake out the system at $\sim 200^{\circ} \mathrm{C}$ for 12 hours, obtaining the vacuum down to $\sim 10^{-8}$ mbar (Madanat et al., 2015; Mousa, 2007).

The commonest method of investigating emitter behavior is to measure current-voltage (I-V) characteristics and extract one or more characterization parameters from FN plot (i.e., a plot of the form $\operatorname{In}\left(\mathrm{I} / \mathrm{V}^{2}\right)$ vs. $1 / \mathrm{V}$, or using equivalent using other variables (Forbes et al., 2015).

\section{RESULTS}

In operation, the field emission microscope (FEM) applied
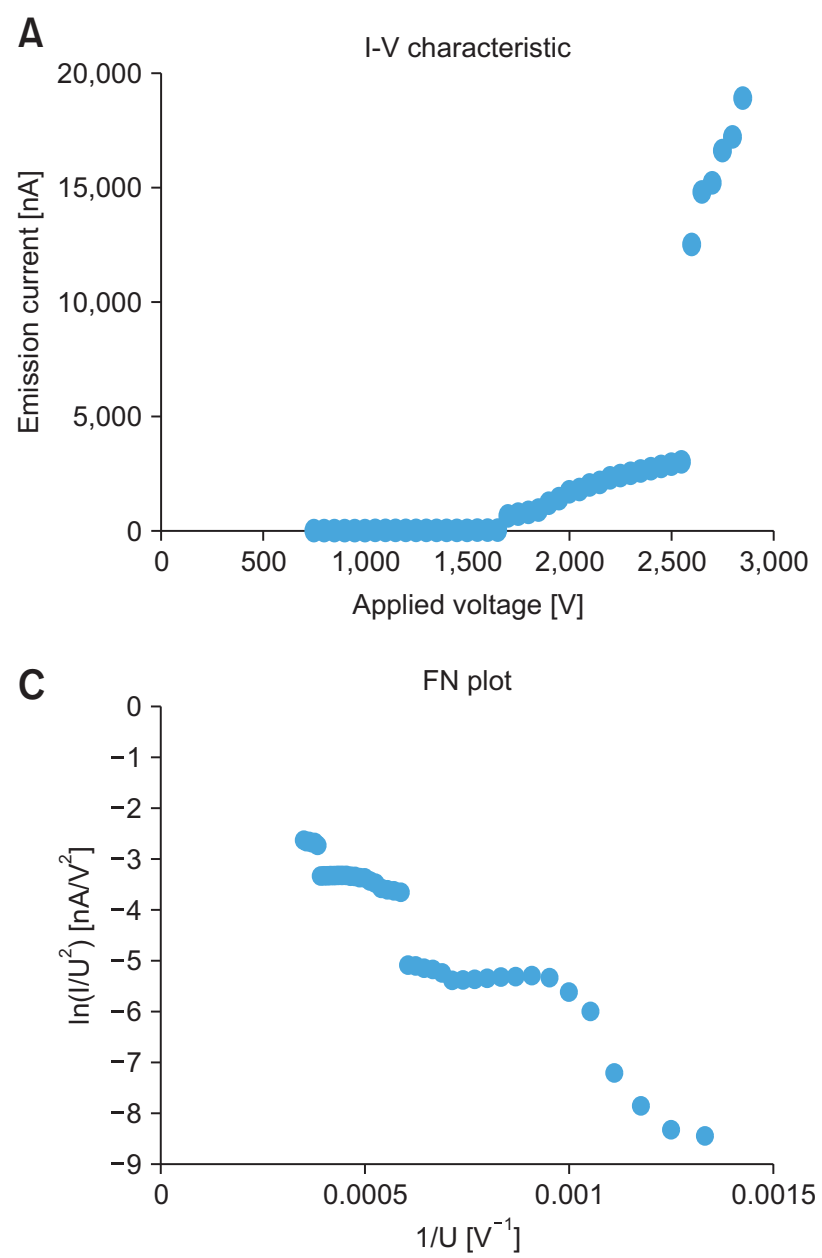

voltage $(\mathrm{V})$ is increased slowly until a "switch on voltage" $\left(\mathrm{V}_{\mathrm{SW}}\right)$ is reached where the emission current suddenly changes from an effective zero to saturation value $\left(\mathrm{I}_{\mathrm{SAT}}\right)$, then

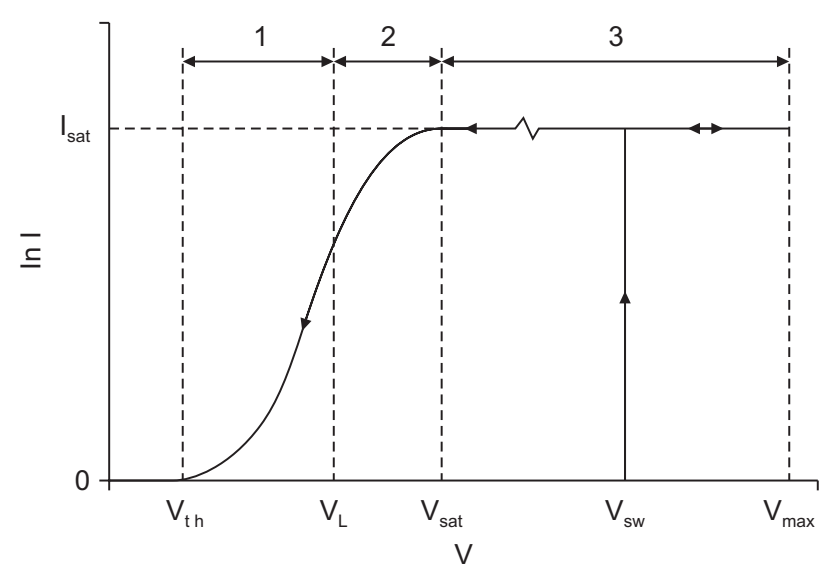

Fig. 3. The generalized form of the current-voltage (I-V) characteristics.
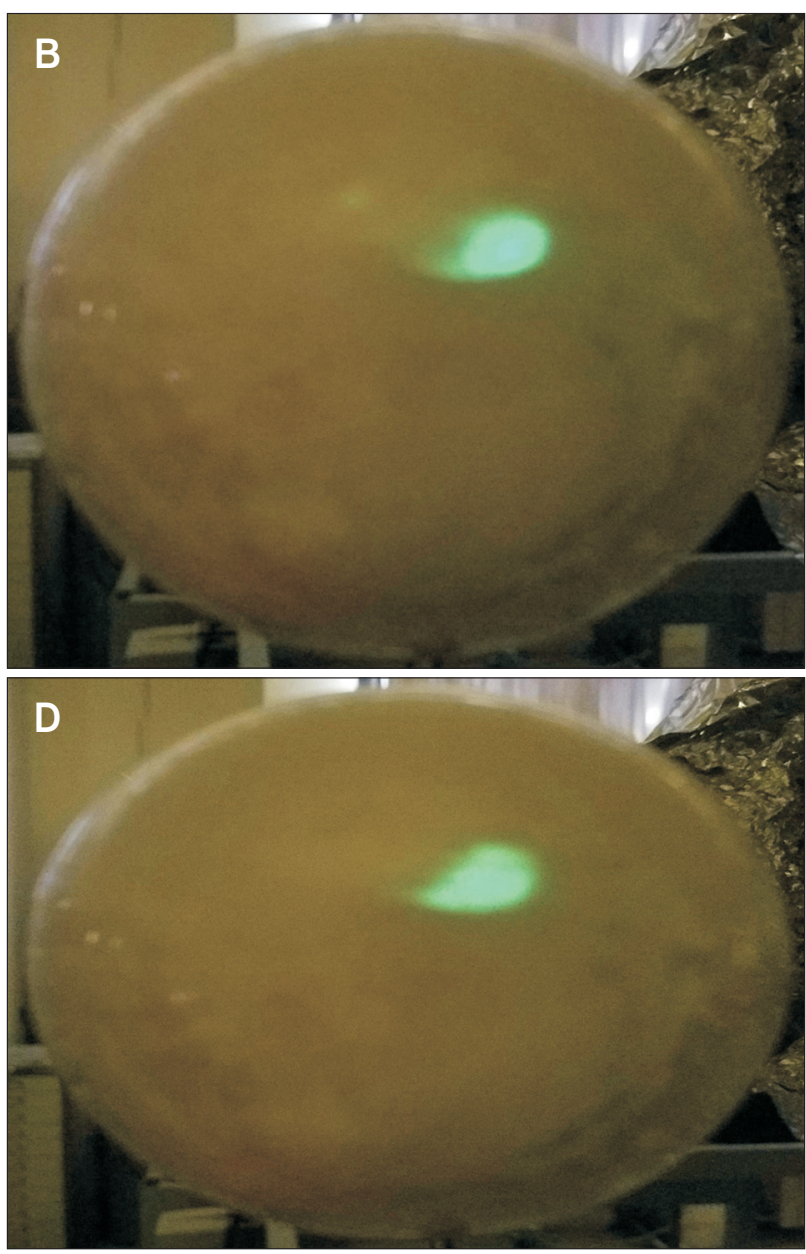

Fig. 4. Increasing voltage CNT-10. (A) Current-voltage (I-V) characteristics shows $V_{S W}=2,550 \mathrm{~V}, \mathrm{I}_{\mathrm{SW}}=3 \mu \mathrm{A}$. (B) Emission image at $\mathrm{V}_{\mathrm{SW}}$. (C) Fowler-Nordheim (FN) plot with slope -9256.25. (D) Increasing voltage CNT-10 tip, Emission image V=2,100 V, I=2.0 $\mu \mathrm{A}$. CNT, carbon nanotubes. 

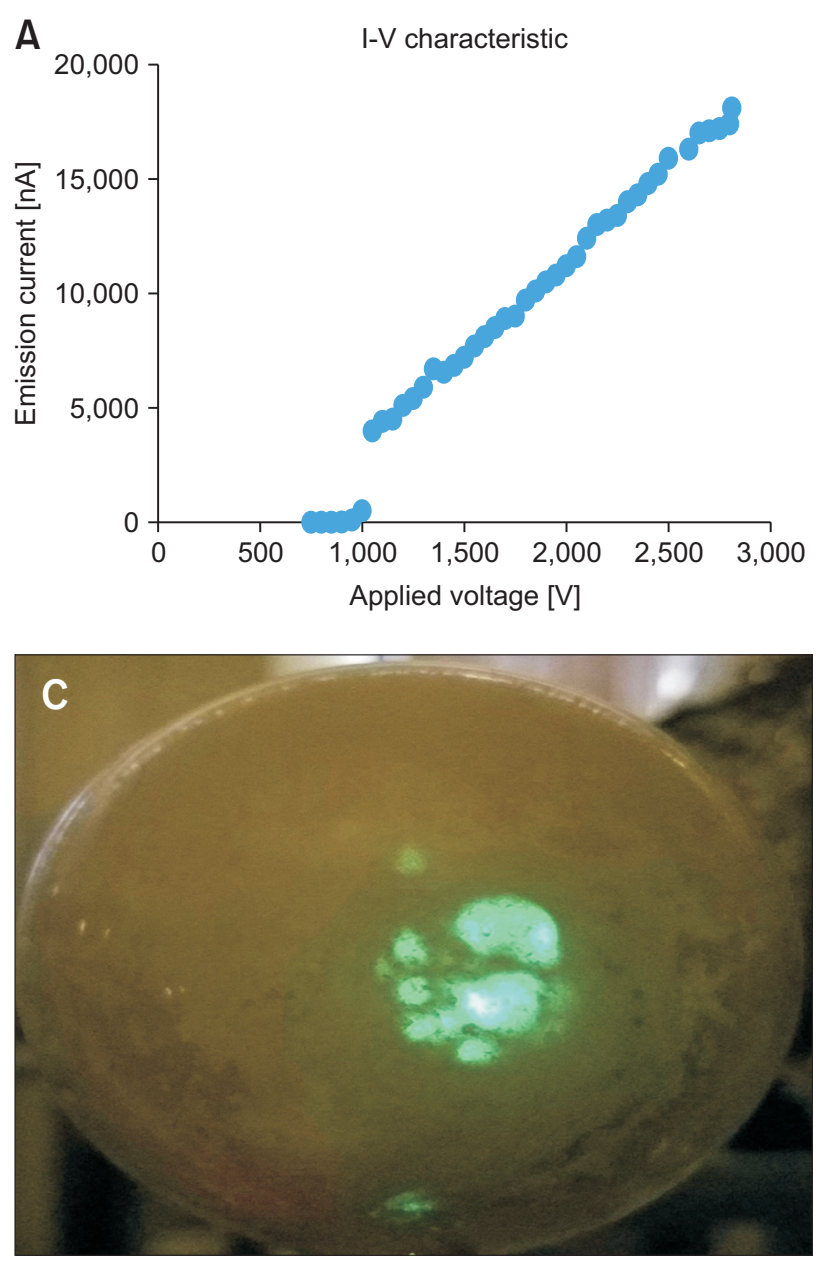

by slowly decreasing the switching voltage to lower value the emission current starts to be decreasing until limit reached, beyond which the emission current falls smoothly to zero as the applied voltage is decreased the threshold value $\left(\mathrm{V}_{\mathrm{TH}}\right)$. However, as shown in Fig. 3, this part of the characteristics can be routinely divided into three region, (region 1) were bounded by the voltage $\left(\mathrm{V}_{\mathrm{L}}\right)$ and the threshold voltage $\left(\mathrm{V}_{\mathrm{TH}}\right)$, (region 2) bounded by the voltage $\left(\mathrm{V}_{\mathrm{L}}\right)$ and $\left(\mathrm{V}_{\mathrm{SAT}}\right)$ and (region 3) confined between $\left(V_{S A T}\right)$ to $\left(V_{M A X}\right)$ that is the maximum voltage before the tip explodes (Ala'a et al., 2015; Mousa, 1991).

To obtain quantitative information about the microscopic properties of the emitter regime, the total electron emission current (I) has been plotted as a function of the applied voltage $\mathrm{V}$ between the emitter and the anode. Emission characterization will be presented as I-V plots and as the related FN plots. Throughout the experiments, electron emission image has been recorded by means of a digital camera, in order to study the spatial distribution and stability of the emission current. The test was performed under a vacuum pressure of $9 \times 10^{-8} \mathrm{mbar}$.
B

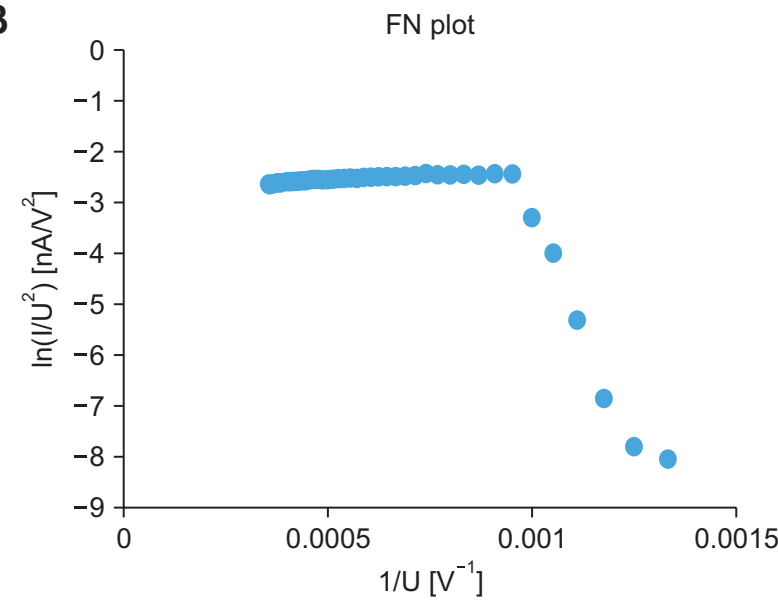

Fig. 5. Decay V CNT-10. (A) Current-voltage (I-V) characteristics shows switch-on at $V_{\mathrm{sw}}=2,810 \mathrm{~V}, \mathrm{I}_{\mathrm{sw}}=18.1 \mu \mathrm{A}$. (B) Fowler-Nordheim (FN) plot. (C) Emission image at $\mathrm{V}_{\mathrm{sw}}$. $\mathrm{CNT}$, carbon nanotubes.

As the voltage increased slowly, in Fig. $4 \mathrm{~A}$ and $\mathrm{C}$, the characteristics of the emitter is shown the electron emission initiated at an applied voltage $=750 \mathrm{~V}$ with current $2 \mathrm{pA}$, and by increasing the applied voltage slowly caused an increasing in emission current, and suddenly the emission current raise to $3 \mu \mathrm{A}$ at voltage value $2,550 \mathrm{~V}$, Fig. $4 \mathrm{~B}$ shows the emission image at $\mathrm{V}_{\mathrm{SW}}=2,550 \mathrm{~V}, \mathrm{I}_{\mathrm{SW}}=3 \mu \mathrm{A}$.

In Fig. 5A, by decreasing voltage slowly, the characteristics of the emitter show that the saturated region extends down to the value $\mathrm{V}_{\mathrm{SAT}}=1,050 \mathrm{~V}$, with $\mathrm{I}_{\mathrm{SAT}}=3.99 \mu \mathrm{A}$, and then started to fall smoothly to $\mathrm{V}_{\mathrm{TH}}=750 \mathrm{~V}$ with $\mathrm{I}=5 \mathrm{pA}$, as shown in Fig. $5 \mathrm{~B}$, once the emitter leaves saturation, the (decreasing) currentvoltage relationship generate an approximately linear FN plot, with slope about -16028.2 decade $\mathrm{V}$.

The experiment was repeated under the same condition. The Fig. 6A shows the relation between current-voltage for the same tip (CNT-10) for both increasing and decreasing voltage, and the current emission image at $\mathrm{V}_{\mathrm{SW}}$ and $\mathrm{V}_{\mathrm{SAT}}$ value. By increasing the applied voltage until point $\mathrm{V}_{\mathrm{SW}}=1,400$ $\mathrm{V}$ was reached the current emission suddenly increased to $\mathrm{I}_{\mathrm{SW}}=5.10 \mu \mathrm{A}$, and by decreasing the voltage, the emission 

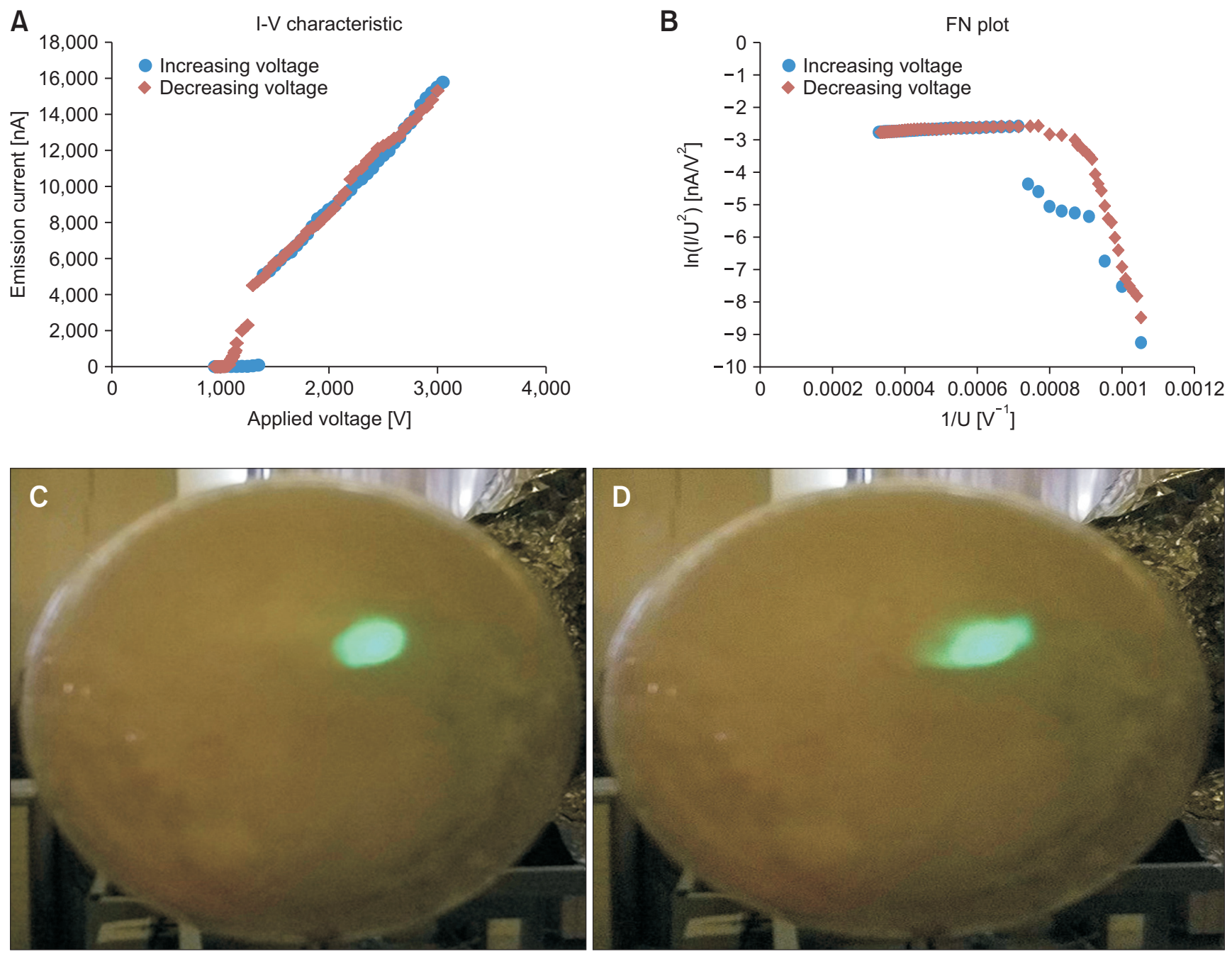

Fig. 6. Increasing and decreasing V CNT-10. (A) Current-voltage (I-V) characteristics. (B) Fowler-Nordheim (FN) plot with slope -32580.8 decayed V. (C) Emission image at 1,340 V. (D) Emission image at $\mathrm{V}_{\mathrm{Sw}}$. CNT, carbon nanotubes.

current saturated to $\mathrm{V}_{\mathrm{SAT}}=1,150 \mathrm{~V}$ with $\mathrm{I}_{\mathrm{SAT}}=1.30 \mu \mathrm{A}$, by further decreasing the voltage, the emission current continue decreasing until $\mathrm{V}_{\mathrm{TH}}=950 \mathrm{~V}$ was reached with current emission value $30 \mathrm{pA}$, then it vanishes.

Studies also carried out on a second tip (CNT-11) where Fig. 7 shows the optical micrograph to it at $50 \times$ magnifications, which is shows the protrude CNT from it under a vacuum pressure of $3 \times 10^{-8}$ mbar, the voltage was applied and the I-V characteristics were recorded. Emission started at $500 \mathrm{~V}$ with current $10 \mathrm{pA}$, by increasing the applied voltage slowly the current emission suddenly increased at applied voltage value $\mathrm{V}_{\mathrm{SW}}=1,700 \mathrm{~V}$ with current emission $\mathrm{I}_{\mathrm{SW}}=8.7 \mu \mathrm{A}$. Fig. 8 shows the related plots. By decreasing the applied voltage the I-V characteristics and FN plot as shown in Fig. 9 that the emitter (CNT-11) shows saturation in current emission at applied voltage $\mathrm{V}_{\mathrm{SAT}}=850 \mathrm{~V}$, with $\mathrm{I}_{\mathrm{SAT}}=1.18 \mu \mathrm{A}$. Fig. $10 \mathrm{C}$ shows the emission image at multiple applied voltages.

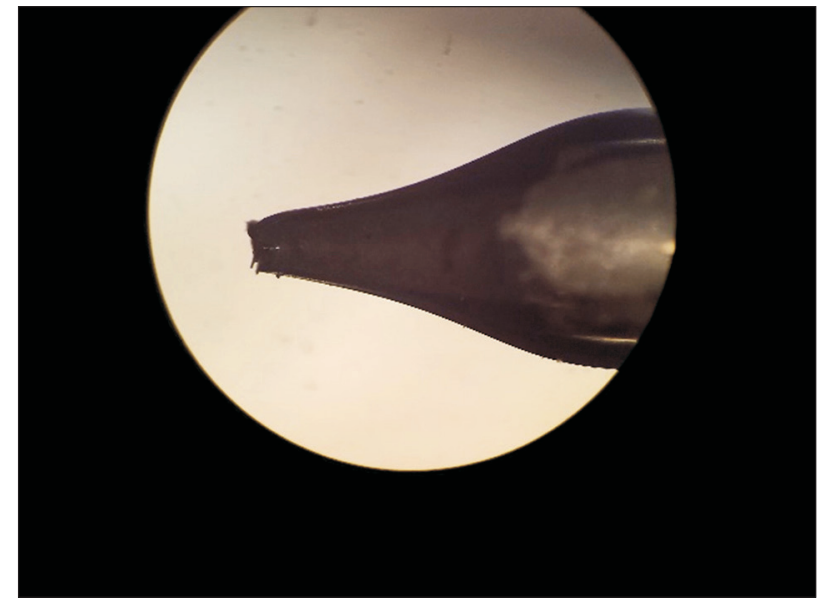

Fig. 7. CNT-11 optical micrograph at 50× magnification. CNT, carbon nanotubes. 

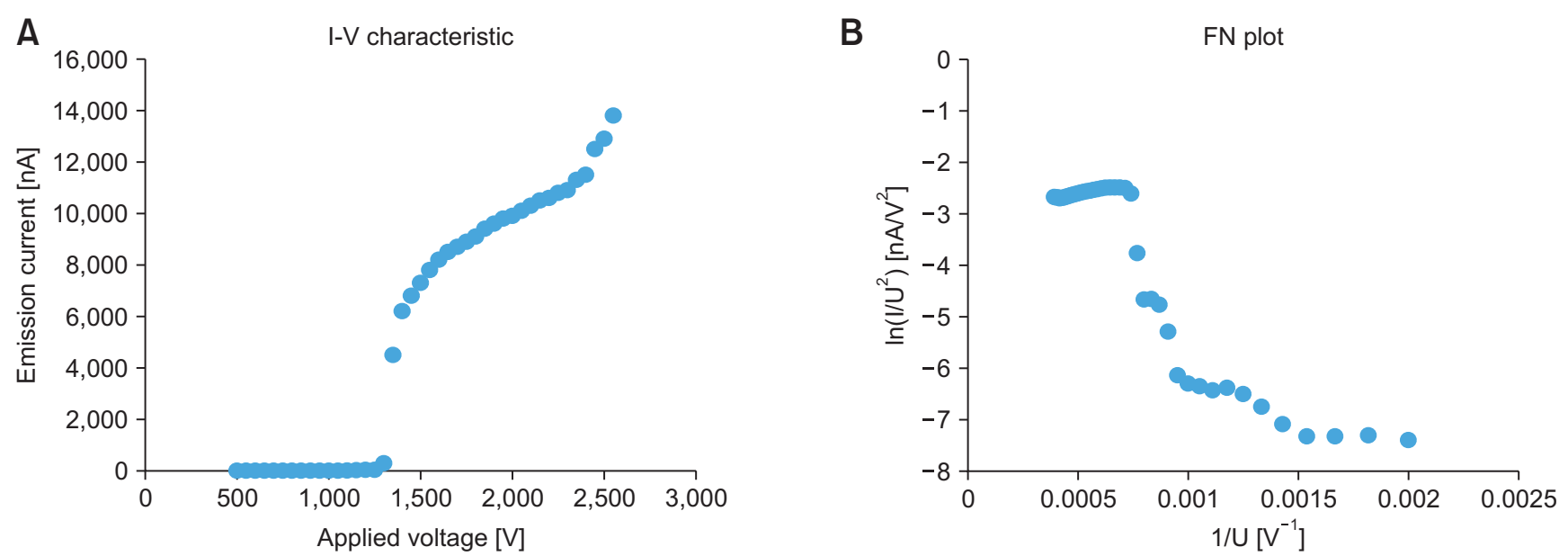

Fig. 8. Emitter (CNT-11), increasing voltage. (A) Current-voltage (I-V) characteristics. (B) Related Fowler-Nordheim (FN) plot. The applied voltage is in range of 500 to 2,550 V. CNT, carbon nanotubes.
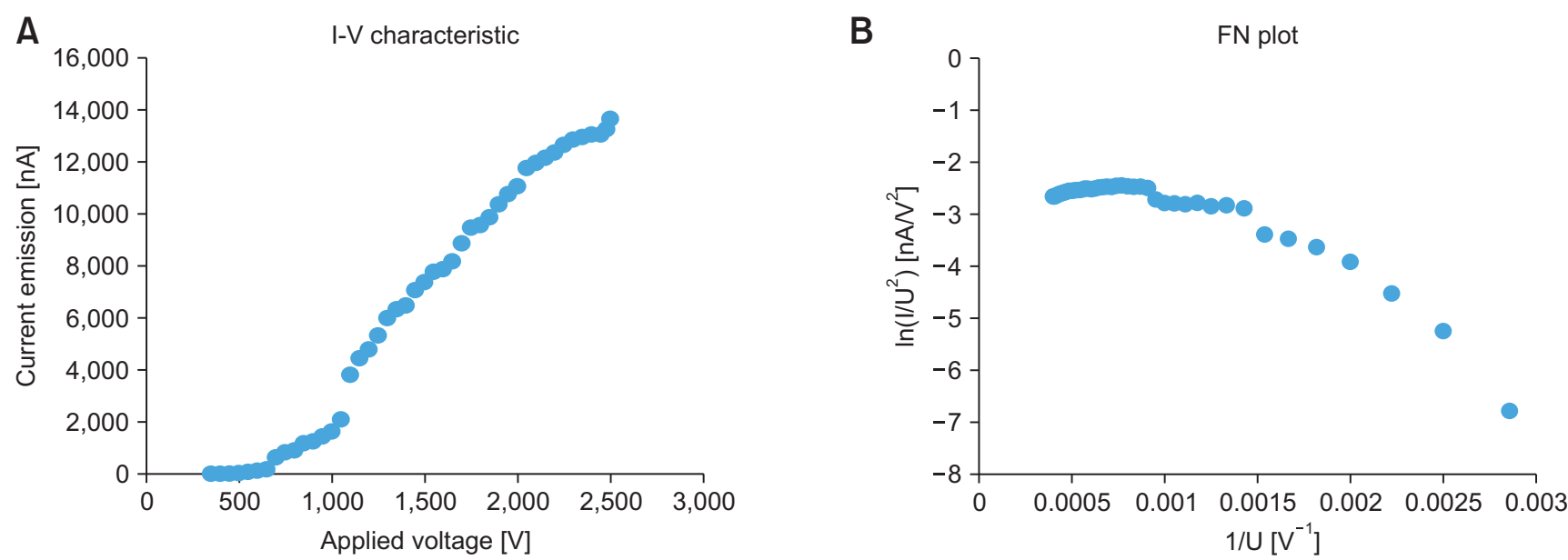

Fig. 9. Emitter (CNT-11), decay V. (A) Current-voltage (I-V) characteristics. (B) Related Fowler-Nordheim (FN) plot with slope about -2533.33. CNT, carbon nanotubes.
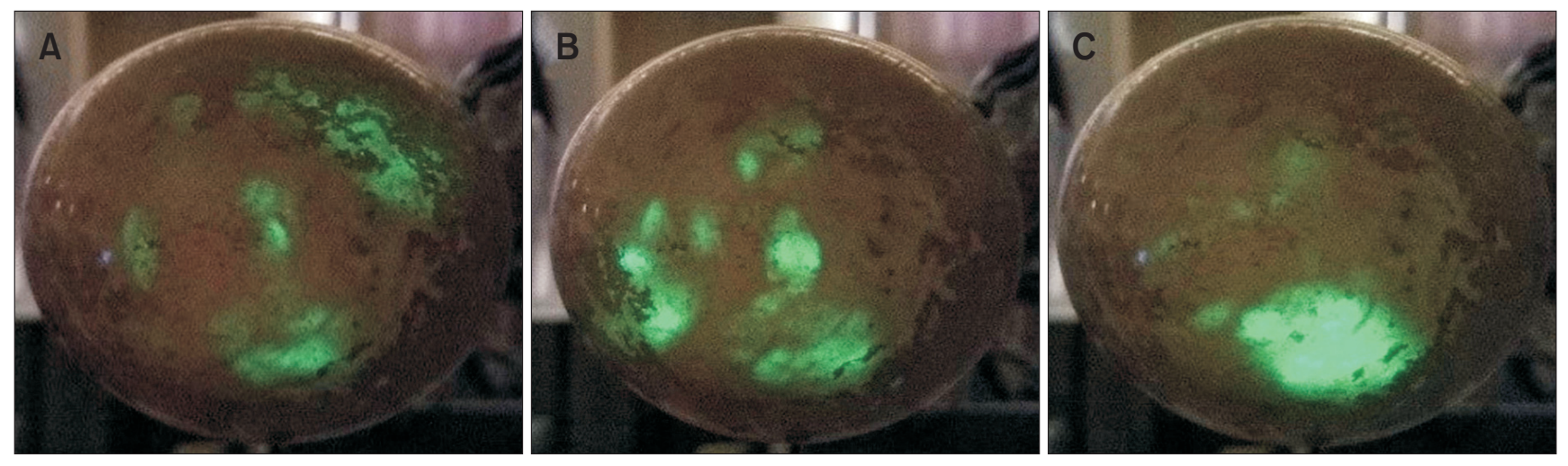

Fig. 10. Decreasing voltage, emission images. (A) V=2,450 V, I=13.1 $\mu$ A. (B) $V=2,480 \mathrm{~V}, \mathrm{I}=13.3 \mu \mathrm{A}$. (C) V=2,500 V, I=13.7 $\mu \mathrm{A}$.

The experiment was repeated after allowing relaxation which we leave the sample under vacuum for 5 hours with no applied voltage at same vacuum pressure value. The current- voltage characteristics Fig. 11 shows initiation by low current emission at $500 \mathrm{~V}$, with an emission current of $1 \mathrm{~Pa}$, as shows the switch-on at $\mathrm{V}_{\mathrm{SW}}=1,600 \mathrm{~V}, \mathrm{I}_{\mathrm{SW}}=3.1 \mu \mathrm{A}$, we increased the 

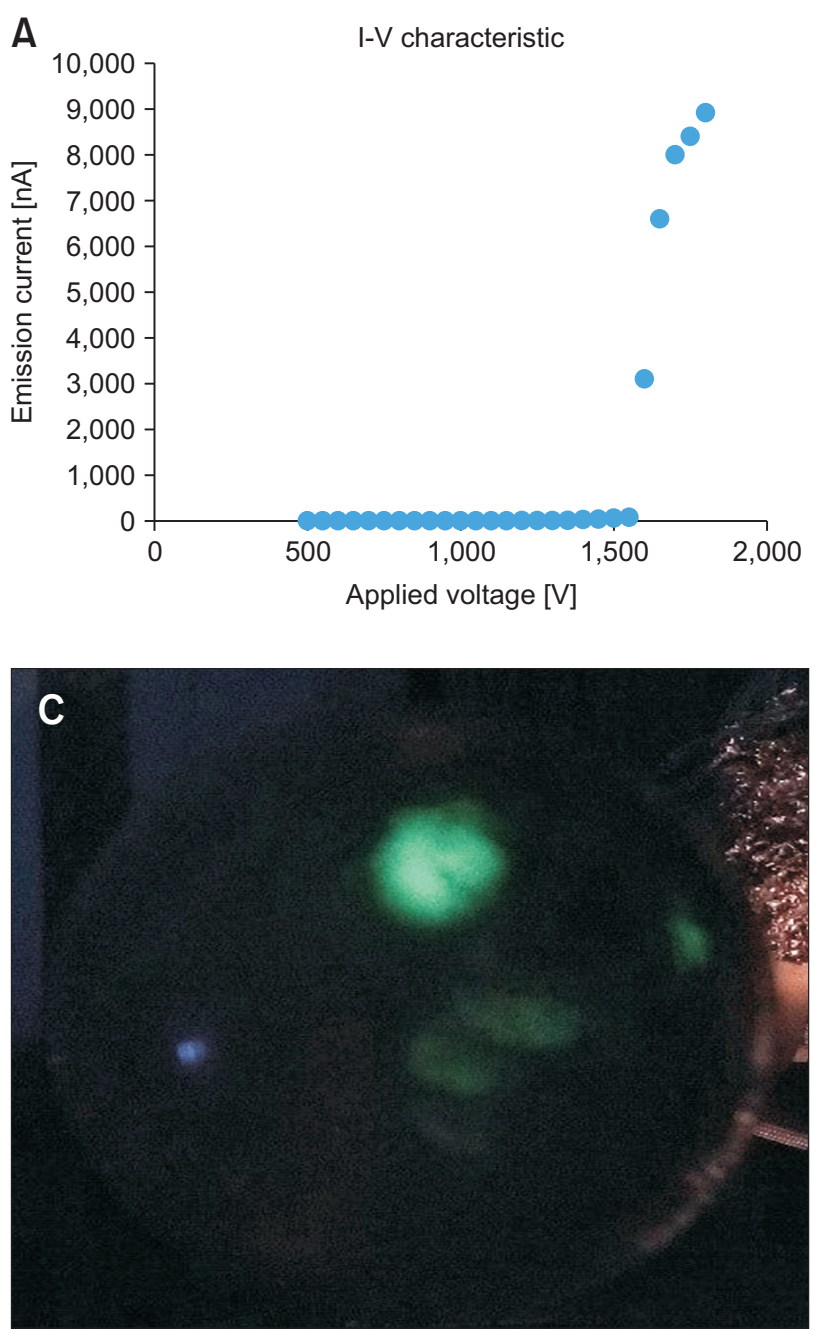

applied voltage to $\mathrm{V}=1,800 \mathrm{~V}$, it gave emission current 8.92 $\mu \mathrm{A}$. As the voltage reduced, the "saturated" region extends down to value $\mathrm{V}_{\mathrm{SAT}}=800 \mathrm{~V}, \mathrm{I}_{\mathrm{SAT}}=1.8 \mu \mathrm{A}$ as it appeared in Fig. 12. Further voltage reduction causes the emission current to fall to nearly zero, reaching the threshold voltage $\mathrm{V}_{\mathrm{TH}}=450 \mathrm{~V}$, $\mathrm{I}_{\mathrm{TH}}=6 \mathrm{pA}$.

\section{DISCUSSION}

It is helpful to attempt to understand the conditions under which continuous stable current may flow from the composite emitters. The electron emission dynamics is mostly controlled by the metal/glass interface. Our experiment shows that we can obtain high emission current from SWCNTs. Some of the emitters experienced some fluctuation and some of them show a stable emission current at high emission current.

\section{CONCLUSIONS}

There is fluctuation in the emission current due to the
B

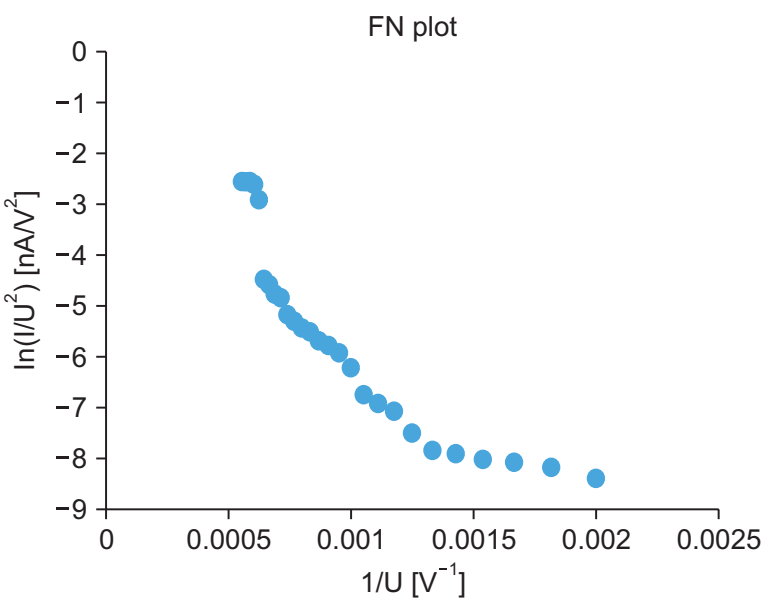

Fig. 11. Increasing voltage, tip CNT-11. (A) Current-voltage (I-V) characteristics. (B) Fowler-Nordheim (FN) plot. (C) Emission image at $\mathrm{V}=1,800 \mathrm{~V}, \mathrm{I}=8.92 \mu \mathrm{A}$. CNT, carbon nanotubes.

nonmetallic nature of the tip, field penetration and fluctuations of the applied potential shift the position of the emitting level, the other possibility is because of the structure of the cap, whereas it is well-known that small changes in adsorbate coverage result in large variations of the work function (Minoux et al., 2005), that could lead to observed saturation at high applied voltages and strong instabilities of the emission in some voltages ranges (Binh et al., 1996; Swanson \& Bell, 1973), once the adsorbates removed, the emission current will be reduced because these adsorbates enhanced the field emission current of nanotube by two or three order (Dean \& Chalamala, 2000) and the deviation from FN equations will disappear.

The effect of relaxation process on field emission process from SWCNT could reduce the VSW as we observed in CNT-11.

\section{CONFLICT OF INTEREST}

No potential conflict of interest relevant to this article was reported. 

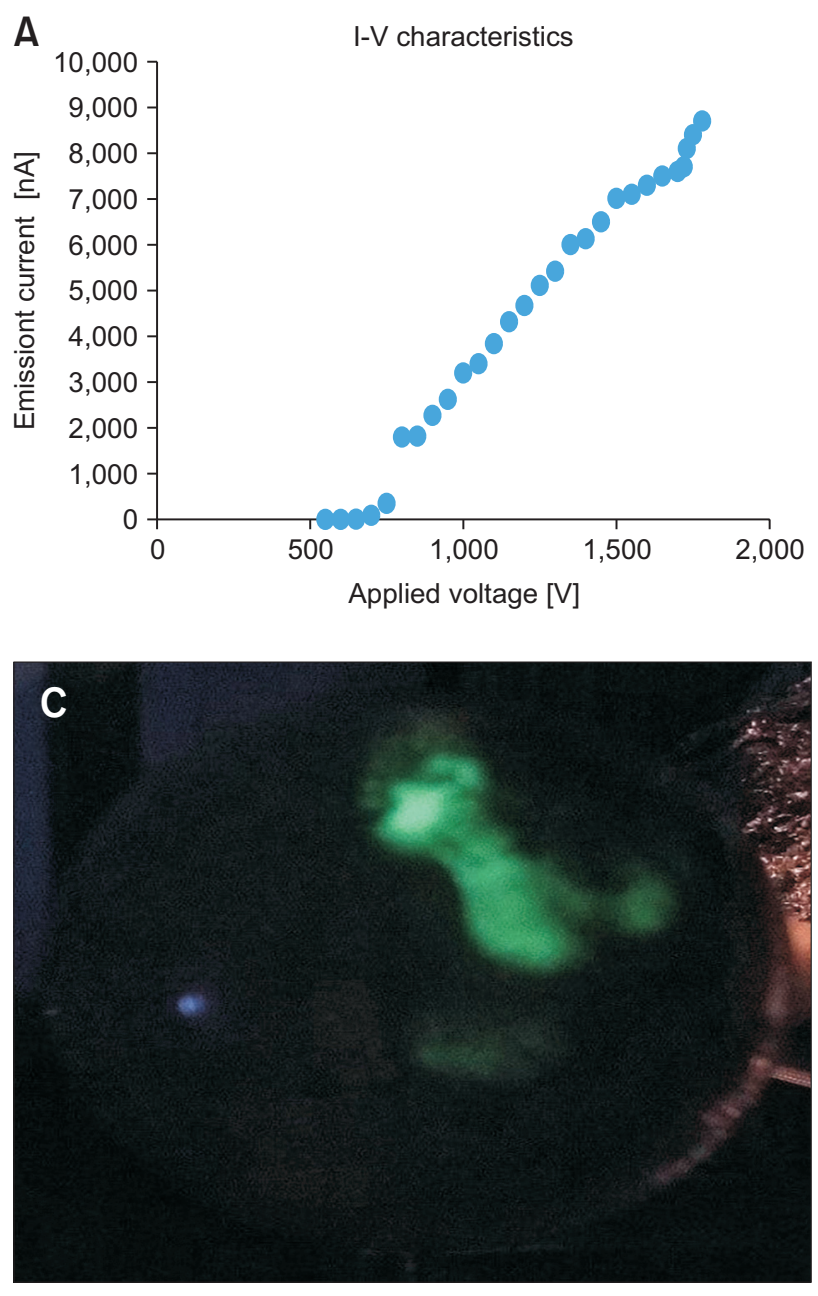

\section{ACKNOWLEDGMENTS}

The authors would like to thank Deanship of the Academic
B

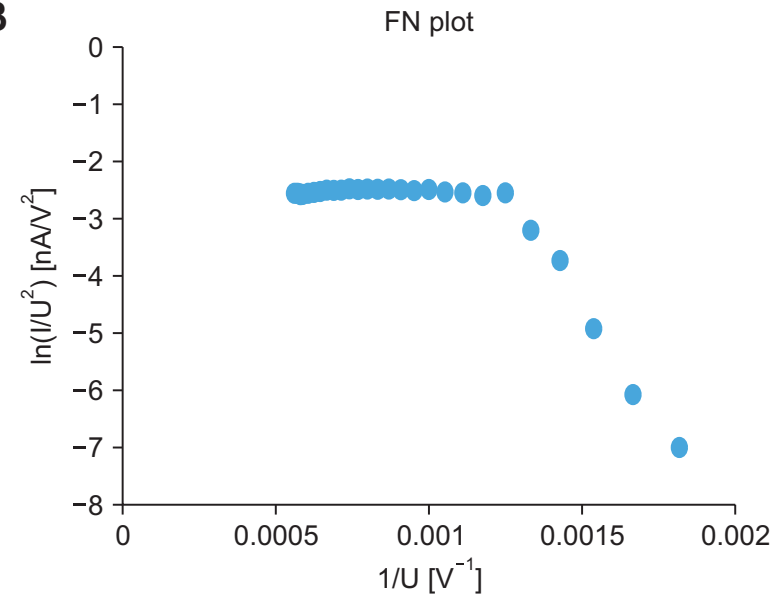

Fig. 12. Decay V, (CNT-11). (A) Current-voltage (I-V) characteristics. (B) Fowler-Nordheim (FN) plot. (C) Field electron microscope image at $\mathrm{V}=1,730 \mathrm{~V}, \mathrm{I}=8.1 \mu \mathrm{A}$. CNT, carbon nanotubes.

Research at Mu'tah University for supporting this work. Authors acknowledge Prof. Dr. M-Ali H. Al-Akhras for providing the SWCNTs and CNTFs.

\section{REFERENCES}

Ala'a A A L Q, Marwan S M, and Fischer A (2015) Effect of insulating layer on the field electron emission performance of nano-apex metallic emitters. IOP Conf. Ser.: Mater. Sci. Eng. 92, 012021.

Bani Ali E and Mousa M (2016) Switch-on phenomena and field emission from multi-walled carbon nanotubes embedded in glass. Appl. Microsc. 46, 244-252.

Binh V, Garcia N, and Purcell ST (1996) Electron field emission from atomsources: fabrication, properties, and applications of nanotips. Adv. Imaging Electron Phys. 95, 83-153.

Cheng Y and Zhou O (2003) Electron field emission from carbon nanotubes. Comptes Rendus Physique 4, 1021-1033.

Dean K A and Chalamala B R (2000) Current saturation mechanisms in carbon nanotube field emitters. Appl. Phys. Lett. 76, 375-377.
Edgcombe C (2005) Development of Fowler-Nordheim theory for a spherical field emitter. Phys. Rev. B 72, 045420.

Edgcombe C J and Jonge $\mathrm{N} \mathrm{d}$ (2007) Deduction of work function of carbon nanotube field emitter by use of curved-surface theory. J. Phys. D: Appl. Phys. 40, 4123.

Forbes R G (2010) Simple derivation of the formula for Sommerfeld supply density used in electron-emission physics and limitations on its use. J. Vac. Sci. Technol. B, Nanotechnol. Microelectron.: Mater., Proc., Measurement Phenom. 28, 1326-1329.

Forbes R G (2012) Extraction of emission parameters for large-area field emitters, using a technically complete Fowler-Nordheim-type equation. Nanotechnology 23, 095706.

Forbes R G, Deane J H B, Fischer A, and Mousa M S (2015) FowlerNordheim plot analysis: a progress report. Jordan J. Phys. 8, 125- 
147.

Hong P N, Thang B H, Hong N T, Lee S, and Minh P N (2009) Electron field emission characteristics of carbon nanotube on tungsten tip. J. Phys.: Conf. Ser. 187, 012041.

lijima S. Helical microtubules of graphitic carbon. Nature 354, 56-58.

Kyritsakis A and Xanthakis J (2014) Derivation of a generalized FowlerNordheim equation for nanoscopic field-emitters. Proc. R. Soc. A 471, 20140811.

Madanat M, Mousa M, Al-Rabadi A, and Fischer A (2015) Electron microscopy-based performance evaluation of various tungsten fieldemitter tips Apex radii. Jordan J. Phys. 8, 79-85.

Marwan S M, Shadi A, Mazen A M, and Anas N A R (2015) Investigating of the field emission performance on nano-apex carbon fiber and tungsten tips. IOP Conf. Ser.: Mater. Sci. Eng. 92, 012022.

Minoux E, Groening O, Teo K B K, Dalal S H, Gangloff L, Schnell J P, Schnell J P, Hudanski L, Bu I Y, Vincent P, Legagneux P, Amaratunga G A, and Milne W I (2005) Achieving high-current carbon nanotube emitters. Nano Lett. 5, 2135-2138.

Modinos A (1984) Field, Thermionic, and Secondary Electron Emission Spectroscopy (Springer US).

Mousa M S (1991) Effect of an internally conductive coating on the electron emission from glass tips. Surf. Sci. 246, 79-86.

Mousa M S (2007) Influence of a dielectric coating on field electron emission from micro-point electron sources. Surf. Interface Anal. 39, 102-110.

Mousa M S and Hibbert D B (1993) Field emission of electrons from glass tips with internal conducting coats. J. Phys. D: Appl. Phys. 26, 697.

Qin X Z, Wang W L, Xu N S, Li Z B, and Forbes R G (2011) Analytical treatment of cold field electron emission from a nanowall emitter, including quantum confinement effects. Proc. R. Soc. A: Math., Phys. Eng. Sci. 467, 1029.

Saito $Y$ and Uemura S (2000) Field emission from carbon nanotubes and its application to electron sources. Carbon 38, 169-182.

Swanson L W and Bell A E (1973) Recent advances in field electron microscopy of metals. Adv. Electron. Electron Phys. 32, 193-309.

Zhang L, Balzano L, and Resasco D E (2005) Single-walled carbon nanotubes of controlled diameter and bundle size and their field emission properties. J. Phys. Chem. B 109, 14375-14381.

Zuber J D, Jensen K L, and Sullivan T E (2002) An analytical solution for microtip field emission current and effective emission area. J. Appl. Phys. 91, 9379. 